\title{
Pharmaceuticals in the tropics: A quantitative study measuring changes in quantity of the active ingredient and microbiological growth
}

\author{
Bharath Raman ${ }^{1}$, Hana Morrissey ${ }^{2 *}$, Patrick Ball ${ }^{2}$ \\ ${ }^{1}$ Charles Darwin University, Darwin, Australia. \\ ${ }^{2}$ School of Pharmacy, Faculty of Science and Engineering, University of Wolverhampton, United Kingdom.
}

\begin{tabular}{ll} 
ARTICLE INFO & ABSTRACT \\
\cline { 3 - 3 } $\begin{array}{l}\text { Article history: } \\
\text { Received on: } 06 / 04 / 2017 \\
\text { Accepted on: } 22 / 06 / 2017 \\
\text { Available online: } 30 / 09 / 2017\end{array}$ & $\begin{array}{l}\text { Global climate change is challenging for the pharmaceutical industry as it is for all other industries, where they } \\
\text { have to select packaging that keep their products stable. The aim of this study was to investigate the effect of a } \\
\text { tropical environment on pharmaceutical preparations in repackaged containers using the drug in the original } \\
\text { container as control. This study concluded that in a tropical environment, some immediate release medications, } \\
\text { underwent significant changes in their physical characteristics, and a less significant loss of efficacy. Bacterial } \\
\text { and fungal growth inside and outside packages used in re-packaging and on the tablet surface occurred after four } \\
\text { Key words: }\end{array}$ \\
$\begin{array}{l}\text { Storage conditions, } \\
\text { pharmaceuticals stability, } \\
\text { microbial growth, } \\
\text { temperature and humidity, } \\
\text { medications. }\end{array}$ & $\begin{array}{l}\text { the risk of patients' non-adherence due to the regimen complexity of chronic disease therapy. On discharge, } \\
\text { hospitals dispense between three and seven days' supply of medication, usually in plastic bottles or sometimes } \\
\text { plastic bags, as a cost-saving measure. Re-packaging of medications is currently common practice, to } \\
\text { personalizes medication for individual patients. This preliminary study demonstrated that products stored in } \\
\text { tropical conditions, changed in their characteristics and gained microbial contamination during the process or } \\
\text { repacking. Further research is required to fully characterize the problem. }\end{array}$ \\
\hline
\end{tabular}

\section{INTRODUCTION}

Packaging is one of the largest industries in the world. All producers of goods for human consumption, including the pharmaceutical industry, face challenges in providing packaging that keeps products attractive to consumers but protected from the climate. Storage conditions for pharmaceuticals are usually standardized to suit the formulation however, this only apply to the product in manufacturer containers or packs (Liu et al., 2011; Feng et al., 2014). To improve patient adherence, multiple-dose compartment administration aids (re-usable or disposable) are used to alleviate the risk of non-adherence due to the complexity of chronic disease therapy, poor health literacy or cognitive impairment. Additionally, hospitals only dispense between three and seven days' medication to save costs, usually

* Corresponding Author

E-mail: hana.morrissey@wlv.ac.uk in plastic bottles or bags. The stability of medications and possible microbial growth on the solid form (tablets or capsules) when repackaged out of the original container into another during dispensing is not guaranteed by the manufacturer. This study investigated the stability of pharmaceuticals in different packaging when used to improve patient adherence or for partial supply from a full pack. Currently, 85\% of manufacturers in Europe use blister packs (Pilchik, 2000a; Pilchik, 2000b) whereas in the United States of America (USA) the majority of over the counter and prescribed medications are repackaged from large containers of up to 1000 tablets into smaller bottles according to the required quantity, either manually or by robots (Zadbuke et al., 2013). The use of blister packaging is becoming more recognized in the USA as it can provide product integrity, product protection, tamper evidence, reduced possibility of accidental use and patient adherence.

The microbial quality of pharmaceuticals is influenced by the process used, the environment and the quality of the raw 
materials used during formulation. The incidence of medication contamination, especially those required to be sterile, is known to be related to the nature of the ingredients (whether natural or synthetic), the quality of the vehicle used to manufacture the medications, the container used and the training, care and attitude of personnel involved in their handling (Okunlola, 2007).

Most raw materials for pharmaceutical excipients allow microbial growth, depending on the nutritional properties and moisture content (Gunar, 2011). Accordingly, as part of medications quality assurance process, the microbial presence or contamination load, must be documented. In many tropical countries, pharmaceutical raw materials and final products are subject to be stored in-transit or during use under uncontrolled conditions, and may be dispensed in non-protective packaging or even without any packaging at all, where the average temperature is $30^{\circ} \mathrm{C}$ and the average $\mathrm{RH}$ is $>75 \%$ (Gunar, 2011). Dispensing of tablets and capsules from large packs is a common practice in hospital pharmacies, clinics and nursing homes. Some open large containers take an average of four weeks to be completely dispensed, depending on demand (Akerele and Ukoh, 2011). Unlike the rich literature around microbial contamination in injectable liquids, few studies have been conducted investigating the bioburden on solid oral formulations. Microbiological quality parameters of drugs are closely associated with the safety of their useand the route by which they will be administered (Okunlola, 2007). Drug contamination may occur at any stage during the manufacturing process from the equipment used, raw materials, excipients, method of storage, transportation stages, water use in manufacture, air ventilation or personnel (Department of Health and Human Services US, 2004). Stability testing is a routine procedure performed on medicinal substances and products, and is employed at various stages of product development. In early stages, accelerated stability testing (at relatively high temperatures and/or humidity) is used to determine the type of degradation that may be found after long-term storage (International Council for Harmonization Expert Working Group, 2009; Feng et al., 2015). Shelf life is the time during which the product, if stored appropriately as per the manufacturer's instructions, will retain fitness for use (British Pharmacopoeia vol. IV, 2008; Grimm, 1998). In addition to the specific shelf life indicated by the manufacturer, some medications prepared in the pharmacy or the ward must follow the limits set up by the different pharmacopoeias, definitions such as 'freshly prepared' (use within 24 hours of preparation) or 'recently prepared' (can be used for up to four weeks if stored at $15-25^{\circ} \mathrm{C}$ ) (International Council for Harmonization Expert Working Group, 2009). For new drugs, it is normal practice to grant only a two-year expiry date when the product is first registered. This is based on satisfactory one-year long-term and six-month accelerated stability data (Bentley, et al. 2015). The expiry date for third and later years is allowed only on production of real-time data for the subsequent years (Bentley et al., 2015). Most pharmaceutical products are characterized by one shelf life. However, in some cases a product may have a shelf life before constitution and another after opening (e.g. reconstituted antibiotics suspensions or injection, or eye preparations) (Bentley et al., 2015). Chemical kinetics refers to the rate of chemical change during a chemical reaction (Charde, 2014).

The Mean Kinetic Temperature (MKT) is the single calculated temperature at which the total amount of degradation over a particular period is equal to the sum of the individual degradations that would occur at various cycles of higher and lower temperature (Charde, 2014). It is an isothermal storage temperature that simulates the non-isothermal effects of storage temperature variation (Charde, 2014). The MKT takes into account seasonal and daily temperature variations during a year. It expresses the cumulative thermal stress undergone by a product at varying temperatures during storage and distribution (Charde, 2014; Bottand Oliveira, 2009).

As world populations age, patients may require assistance in medication adherence and residential home staff may require support in managing their residents' medications (NiDirect Government Services, 2017). As medication use increases with advancing age, nursing/residential homes rely on pharmacy services to support their aging residents (Edirisinghe, 2015). Monitored dosage systems (MDS) and medicine compliance aids (MCA) or dose administration aids (DAA) have been supplied to improve patient adherence with prescribed medications for those having difficulties managing their medications (The international pharmacopoeia, vol. 5, 2013). Those aids are prepared and supplied by pharmacists. There is ongoing debate about drug stability in MDS, MCA and DAA (Akerele and Ukoh, 2011) Since there is limited short-term stability data for medications in MCAs (Akerele and Ukoh, 2011). In Australia, DAAs are commonly used for older patients and for Indigenous Australians living in remote communities.

\section{AIM}

The aim of this study was to investigate the effect of a tropical environment on pharmaceutical preparations in original (control) and repackaged containers.

\section{METHODS AND DESIGN}

This was a preliminary study to explore the stability and sterility of pharmaceuticals stored in a tropical environment. Using a temperature and humidity controlled cabinet, the study simulated the weather in Darwin NT Australia in the wet season at $30^{\circ} \mathrm{C}$, $80 \%$ RH (Figures 1 and 2), which is routinely seen in the houses and buildings where air-conditioning is not available or when the patient is living outdoors and medication is directly exposed to heat, humidity, direct sunlight, soil or rain (e.g., Indigenous Australians living in remote communities). This study tested the stability of a range of pharmaceuticals through quantifying the amount of API through absorbance spectrophotometry, the changes in physical characteristics such as appearance, disintegration, hardness and $\mathrm{pH}$; and the surface microbiological growth after exposure to the study prescribed heat and humidity form the supplier for up to 24 weeks. 


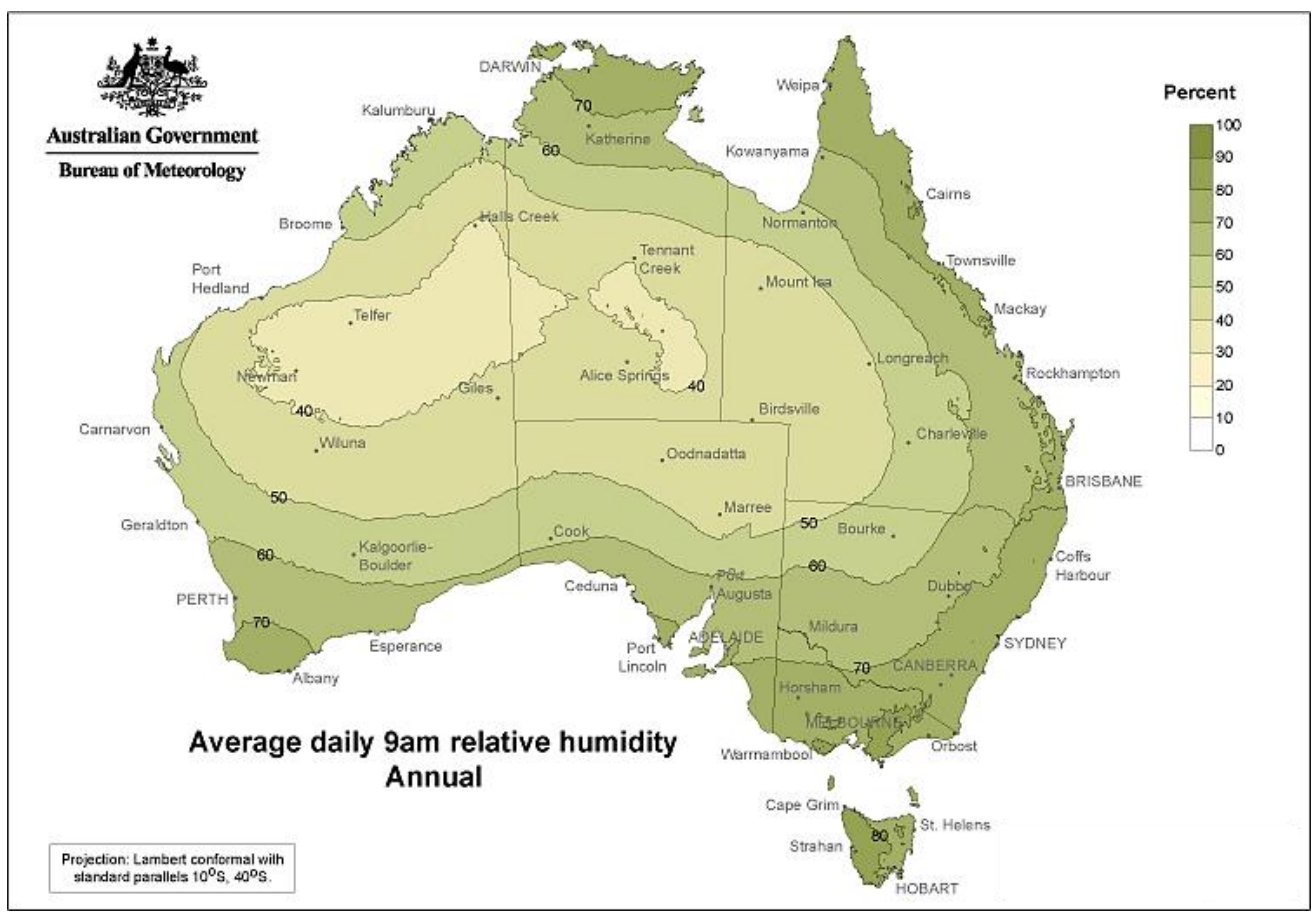

Fig. 1: Average daily 9 am relative humidity in Australia (Image Source: Bureau of Meteorology, Australia).

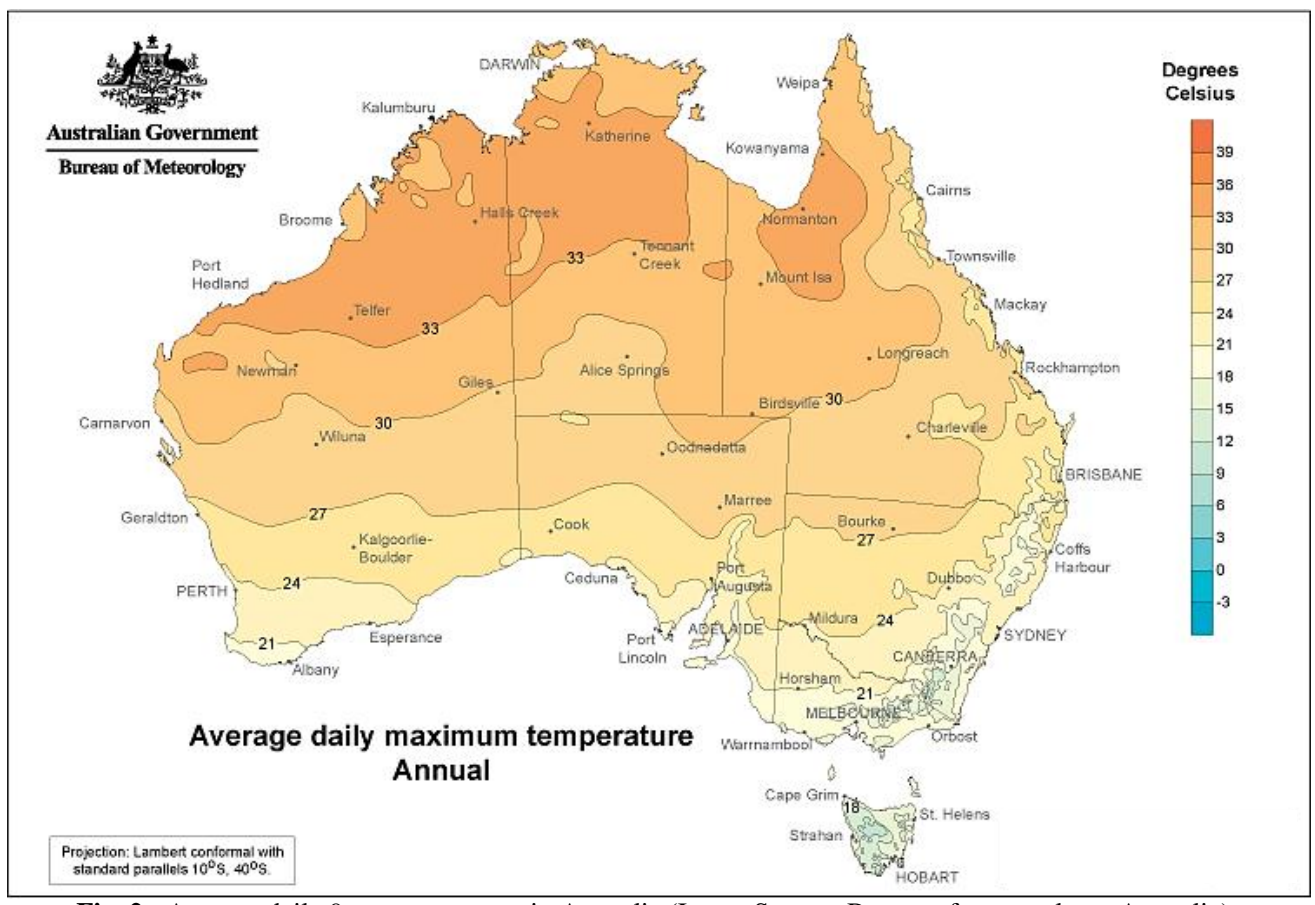

Fig. 2: Average daily 9 am temperature in Australia (Image Source: Bureau of meteorology, Australia).

All testing was conducted at Charles Darwin University laboratory. The equipment used, consumables and personal protective equipment are listed in table 1.

The study was designed and conducted over three phases -Phase 1: preparation of material and workplace, Phase 2: creation and validation of the of the absorbance calibration curves, baseline microbial growth, physical appearance, $\mathrm{pH}$ and re-packaging of samples, Phase 3:testing stability, microbial growth, physical appearance and $\mathrm{pH}$ after exposure to heat and humidity. Eleven of the medications most commonly prescribed for the treatment of chronic disease, were selected.

Each medication product tested was from a single batch for all samples (Table 2).The absorbance peak for each drug was determined from the literature (Table 3 ). 
Table 1: Equipment and material.

\begin{tabular}{lll}
\hline Purpose & Type & Supplier \\
\hline Equipment & A pH meter & TPS Instruments, Brisbane. \\
& Temperature and Humidity Chambers & TCH-150 and TCH-460, Thermoline Scientific Equipment. \\
& Tablet disintegration apparatus & Electrolab. \\
& UV spectrophotometer & UV-Vis spectrophotometer (Model U-1100), Hitachi Corporation Ltd. \\
& Incubator & Labec Laboratory Equipment. \\
& Microscope & Olympus \\
& Colony counter & Gallenkamp \\
& Tablet Hardness tester & Model:EH01, Oclas Luggage \\
Consumable & Fridge & Thermoline Scientific Equipment \\
& Culture media plates (Nutrient agar and Sabouraud agar plates). & ThermoFisher Scientific \\
& Swabs, Multigate Medical Products & Swabs, Multigate Medical Products \\
& Saline, Baxter 10 ml sachets & Saline, Baxter 10 ml sachets \\
& Reverse osmosis water & Enware \\
Personal protective & Medico-Pack and Webster-Pak ${ }^{\mathrm{TM}}$ \\
equipment & Blister packs & Sarstedt \\
& Bottles & Mediflex \\
& Gloves, sterile, powder and latex free & \\
& Safety glasses & Prosafe \\
& Two-way filter Face mask & Livingstone \\
& Lab coat & Hard Yakka \\
\hline
\end{tabular}

Table 2: Medication procurement information.

\begin{tabular}{|c|c|c|c|c|c|}
\hline Drug & Manufacturer & Strength and Formulation & Batch Number & Expiry Date & AUST-R Number \\
\hline Amiodarone & GenRx & $200 \mathrm{mg}$ tablets & E484 & April 2016 & 80768 \\
\hline Amlodipine & Apotex Private Ltd & $200 \mathrm{mg}$ tablets & MC2450 & September 2017 & 135125 \\
\hline Aspirin & Mayne Pharma & $100 \mathrm{mg}$ tablets & 995528 & August 2016 & 194209 \\
\hline Atorvastatin & Apotex Private Ltd & $80 \mathrm{mg}$ tablets & 33619 & December 2015 & 153729 \\
\hline Gliclazide & GenRx & $80 \mathrm{mg}$ tablets & KW1494 & March 2016 & 80084 \\
\hline Ibuprofen & Abbott Australasia Private Ltd & $400 \mathrm{mg}$ tablets & 49961PC & December 2017 & 80659 \\
\hline Irbesartan & Apotex Private Ltd & $50 \mathrm{mg}$ tablets & 1405002456 & March 2017 & 213310 \\
\hline Metformin & Apotex Private Ltd & $500 \mathrm{mg}$ tablets & ACN4016 & December 2016 & 176509 \\
\hline Paracetamol & Apotex Private Ltd & $500 \mathrm{mg}$ tablets & X40201 & February 2016 & 156815 \\
\hline Prednisolone & Nova Pharmaceuticals Private Ltd & $5 \mathrm{mg}$ tablets & PY54008 & April 2017 & 13469 \\
\hline Sodium Valproate & Winthrop & $200 \mathrm{mg}$ tablets & E002 & December 2017 & 125620 \\
\hline
\end{tabular}

Table 3: Tablet repacks for stability and microbiological testing.

\begin{tabular}{|c|c|}
\hline Time line & Original and repackaged dose administration pack \\
\hline $\begin{array}{l}\text { Day } 1 \text { - on purchase } \\
\text { Create absorbent/concentration curve and establish physical } \\
\text { appearance (photographs and in word description), } \mathrm{pH} \text { and } \\
\text { baseline microbial count }\end{array}$ & One set of three tablets of all 11 medications in original manufacturer's container \\
\hline \multirow[t]{2}{*}{$\begin{array}{l}\text { Re-pack of samples for stability and microbial testing for } \\
\text { duration of } 24 \text { weeks }\end{array}$} & $\begin{array}{l}\text { Four sets of three tablets of all } 11 \text { medications repackaged in bottles and in separate blisters in dose } \\
\text { administration aid packs (Webster-Pak }{ }^{\mathrm{TM}} \& \text { Medico-Pak }{ }^{\mathrm{TM}} \text { ) }\end{array}$ \\
\hline & Incubated in humidity and temperature chamber \\
\hline Week 1 & Three tablets out of an original pack (one tablet for each) x 11 medications \\
\hline \multirow{3}{*}{$\begin{array}{l}\text { Test for stability, microbial growth, physical appearance } \\
\text { and } \mathrm{pH}\end{array}$} & Three tablets (one tablet for each) in bottles x 11 medications \\
\hline & Three tablets (one tablet for each) in Webster-Pak ${ }^{\mathrm{TM}}$ x 11 medications \\
\hline & Three tablets (one tablet for each) in MedicoPak ${ }^{\mathrm{TM}}$ x 11 medications \\
\hline Week 2 & Three tablets out of an original pack (one tablet for each) x 11 medications \\
\hline \multirow{3}{*}{$\begin{array}{l}\text { Test for stability, microbial growth, physical appearance } \\
\text { and } \mathrm{pH}\end{array}$} & Three tablets (one tablet for each) in bottles x 11 medications \\
\hline & Three tablets (one tablet for each) in Webster-Pak ${ }^{\mathrm{TM}} \times 11$ medications \\
\hline & Three tablets (one tablet for each) in MedicoPak ${ }^{\mathrm{TM}}$ x 11 medications \\
\hline Week 4 & Three tablets out of an original pack (one tablet for each) x 11 medications \\
\hline \multirow{3}{*}{$\begin{array}{l}\text { Test for stability, microbial growth, physical appearance } \\
\text { and } \mathrm{pH}\end{array}$} & Three tablets (one tablet for each) in bottles x 11 medications \\
\hline & Three tablets (one tablet for each) in Webster-Pak ${ }^{\mathrm{TM}} \times 11$ medications \\
\hline & Three tablets (one tablet for each) in MedicoPak ${ }^{\mathrm{TM}}$ x 11 medications \\
\hline Month 3 & Three tablets out of an original pack (one tablet for each) x 11 medications \\
\hline \multirow{3}{*}{$\begin{array}{l}\text { Test for stability, microbial growth, physical appearance } \\
\text { and } \mathrm{pH}\end{array}$} & Three tablets (one tablet for each) in bottles x 11 medications \\
\hline & Three tablets (one tablet for each) in Webster-Pak ${ }^{\mathrm{TM}} \times 11$ medications \\
\hline & Three tablets (one tablet for each) in MedicoPak ${ }^{\mathrm{TM}} \times 11$ medications \\
\hline Month 6 & Three tablets out of an original pack (one tablet for each) $\times 11$ medications \\
\hline \multirow{3}{*}{$\begin{array}{l}\text { Test for stability, microbial growth, physical appearance } \\
\text { and } \mathrm{pH}\end{array}$} & Three tablets (one tablet for each) in bottles x 11 medications \\
\hline & Three tablets (one tablet for each) in Webster-Pak ${ }^{\mathrm{TM}} \times 11$ medications \\
\hline & Three tablets (one tablet for each) in MedicoPak ${ }^{\mathrm{TM}}$ x 11 medications \\
\hline
\end{tabular}


Table 4: $\kappa$ max for the 11 selected medications.

\begin{tabular}{|c|c|c|c|}
\hline Drug & Brand & $\Lambda \max (\mathrm{nm})$ & Reference \\
\hline Aspirin & Astrix & 292.0 & $\begin{array}{l}\text { Simultaneous determination of salicylic acid and acetylsalicylic acid in aspirin delayed-release tablet } \\
\text { formulations by second-derivative UV-spectrophotometry. Journal of Pharmaceutical and Biomedical } \\
\text { Analysis. 1998 Dec 1;18(4):871-5. }\end{array}$ \\
\hline Paracetamol & Panadol & 252.8 & $\begin{array}{l}\text { Application of a new spectrophotometric method for the analysis of a ternary mixture containing metamizol, } \\
\text { paracetamol and caffeine in tablets. AnalyticaChimica Acta. } 1998 \text { Feb 19;359(1): } 93-106 \text {. }\end{array}$ \\
\hline Metformin & Diabex & 234.0 & $\begin{array}{l}\text { Determination of metformin in pharmaceutical preparations using potentiometry, spectrofluorimetry and } \\
\text { UV-visible spectrophotometry. AnalyticaChimica Acta. 1999 Jan 4;378(1): 299-311. }\end{array}$ \\
\hline Atorvastatin & Atorvastatin & 246.0 & $\begin{array}{l}\text { Application of UV-spectrophotometry and RP-HPLC for simultaneous determination of atorvastatin } \\
\text { calcium and ezetimibe in pharmaceutical dosage form. Eurasian Journal of Analytical Chemistry. } 2006 \text { Sep } \\
1 ; 1(1) \text {. }\end{array}$ \\
\hline Irbesartan & Irbesartan & 207.0 & $\begin{array}{l}\text { Determination of irbesartan in the presence of } \\
\text { hydrochlorothiazide by derivative spectrophotometry. Journal of Pharmaceutical and Biomedical Analysis. } \\
2002 \text { Jun 20;29(1):299-305. }\end{array}$ \\
\hline Amlodipine & Amlodipine & 360.0 & $\begin{array}{l}\text { Photodegradation monitoring of amlodipine by derivative spectrophotometry. Journal of Pharmaceutical and } \\
\text { Biomedical Analysis. 2002 Jan 1;27(1):19-24. }\end{array}$ \\
\hline Amiodarone & Amiodarone & 305.0 & $\begin{array}{l}\text { Monitoring dissolution rate of amiodarone tablets by a multiple fiber-optic sensor system. Dissolution } \\
\text { Technologies. } 2008 \text { Feb 1;15(1):22. }\end{array}$ \\
\hline Gliclazide & Gliclazide & 228.0 & $\begin{array}{l}\text { Simultaneous UV spectrophotometric method for estimation of gliclazide and metformine hydrochloride in } \\
\text { tablet dosage form. International Journal of ChemTech Research. } 2010 \text { Apr } 2 ;(2): 813-7 .\end{array}$ \\
\hline Ibuprofen & Brufen & 254.2 & $\begin{array}{l}\text { Simultaneous spectrophotometric determination of pseudoephedrine hydrochloride and ibuprofen in a } \\
\text { pharmaceutical preparation using ratio spectra derivative spectrophotometry and multivariate calibration } \\
\text { techniques. Journal of Pharmaceutical and Biomedical Analysis. 2004 Feb 18;34(3):473-83. }\end{array}$ \\
\hline Prednisolone & Panafcortelone & 246.0 & $\begin{array}{l}\text { Development of simultaneous spectrophotometric method of mesalazine and prednisolone in same dosage } \\
\text { form. International Journal of Applied Pharmaceutics. 2010;2(4):8-11. }\end{array}$ \\
\hline $\begin{array}{l}\text { Sodium } \\
\text { Valproate }\end{array}$ & Epilim & 212.0 & $\begin{array}{l}\text { Valproic acid and sodium valproate: comprehensive profile. Profiles of Drug Substances, Excipients, and } \\
\text { Related Methodology. 2005 Dec31;32:209-40. }\end{array}$ \\
\hline
\end{tabular}

In addition to tablets left in their original containers as control undisturbed but labeled as control, repackaged samples were packed according to good pharmaceutical manufacturing practice for the testing sequence showing in table 4. For the purpose of this paper "original container" refers to the control where all results will be compared to.

The method was validated by using the specified method on the batched will be used against two different batches of each product, the results were the same for the three batches and also matched the products manufacturer specifications for API content and physical and chemical characteristics and appearance.

Spectrophotometric calibration curves for the chosen medications were developed and validated on Day-1.

The products from the original containers (control) were tested for appearance, hardness, $\mathrm{pH}$, content of API and for microbiological contamination. As soon as the medications were repackaged, they were placed inside the temperature and humidity chamber at $30{ }^{\circ} \mathrm{C}$ and $80 \%$ RH. A swabbing technique was used to test for microorganisms. The enumeration was done on the outer and inner surface of all four types of packs (original, bottle, Webster-Pak ${ }^{\mathrm{TM}}$ and Medico-Pak ${ }^{\mathrm{TM}}$ ) and tablets used in this study at regular time intervals using a commercially available swab.

They were then transferred to the both nutrient agar and sabouraud agar plates. The plates were pre-marked with all required information such as date and samples details. Nutrient agar plates were incubated for 24 hours for bacterial growth in an incubator at $37^{\circ} \mathrm{C}$, while sabouraud agar plates were incubated at $25 \pm 2^{\circ} \mathrm{C}$ for 72 hours for fungal growth detection in an inoculation hood. Typical colonies of microbial growth on plates were counted at the end of the incubation period with the aid of a Stuart ${ }^{\mathrm{TM}}$ colony counter. This procedure was followed for all the samples. Gram staining was used as part of the identification process.

\section{RESULTS}

\section{Stability testing results Control and baseline}

Sampling and testing was conducted on Day 1, as soon as the products were received from the supplier. Table 5 shows the data used to establish the absorption/concentration curve for all 11 medications tested at concentrations of $100 \%, 75 \%, 50 \%$ and $25 \%$.

Table 5: Standard: Absorption/concentration data

\begin{tabular}{cccccc}
\hline Drug & $\boldsymbol{\lambda} \mathbf{~ m a x}^{*}$ & $\mathbf{1 0 0 \%}$ & $\mathbf{7 5 \%}$ & $\mathbf{5 0 \%}$ & $\mathbf{2 5 \%}$ \\
\hline Amiodarone & $305.0 \mathrm{~nm}$ & 1.90 & 1.40 & 1.00 & 0.60 \\
Amlodipine & $360.0 \mathrm{~nm}$ & 1.60 & 1.00 & 0.70 & 0.40 \\
Aspirin & $292.0 \mathrm{~nm}$ & 1.90 & 1.40 & 0.70 & 0.60 \\
Atorvastatin & $246.0 \mathrm{~nm}$ & 4.60 & 4.40 & 4.30 & 4.20 \\
Gliclazide & $228.0 \mathrm{~nm}$ & 3.50 & 3.45 & 3.44 & 3.42 \\
Ibuprofen & $254.2 \mathrm{~nm}$ & 1.80 & 1.70 & 1.60 & 1.50 \\
Irbesartan & $207.0 \mathrm{~nm}$ & 5.50 & 4.10 & 4.00 & 3.8 \\
Metformin & $234.0 \mathrm{~nm}$ & 3.53 & 3.50 & 3.48 & 3.45 \\
Paracetamol & $252.8 \mathrm{~nm}$ & 4.40 & 4.30 & 4.20 & 4.10 \\
Prednisolone & $246.0 \mathrm{~nm}$ & 3.38 & 3.36 & 3.33 & 3.29 \\
Sodium Valproate & $212.0 \mathrm{~nm}$ & 4.20 & 4.00 & 3.90 & 3.70 \\
\hline
\end{tabular}

Note: $* \lambda$ max for each product was sourced from the product information document.

Table 6 presents the physical characteristics for each product at baseline on Day-1. All results conformed to the 
published product information for each of the 11 medications tested. Tables 7 to 10 contains results for all tested parameters.

Table 6: Standard: Physical characteristics.

\begin{tabular}{llll}
\hline Drug & $\mathbf{p H}$ & Break-point & Dissolution \\
\hline Amiodarone & 4.0 & 114.2 & $3: 02 \mathrm{sec}$ \\
Amlodipine & 5.5 & 95.6 & $0: 36 \mathrm{sec}$ \\
Aspirin & 3.0 & 30.0 & $0: 27 \mathrm{sec}$ \\
Atorvastatin & $7 ; 0$ & 184.0 & $6: 32 \mathrm{sec}$ \\
Gliclazide & 5.5 & 146.5 & $2: 38 \mathrm{sec}$ \\
Ibuprofen & 4.5 & 166.3 & $5: 80 \mathrm{sec}$ \\
Irbesartan & 5.5 & 39.5 & $4: 11 \mathrm{sec}$ \\
Metformin & 6.5 & 349.5 & $11: 35 \mathrm{sec}$ \\
Paracetamol & $6: 0$ & 457.2 & $2: 21 \mathrm{sec}$ \\
Prednisolone & 5.5 & 39.5 & $1: 38 \mathrm{sec}$ \\
Sodium Valproate & 6.0 & 143.7 & $1: 25: 53 \mathrm{sec}$ \\
\hline
\end{tabular}

Metformin

The largest changes in the API level were seen in the repackaged bottles for $\mathrm{pH}$, major changes occurred in MedicoPak ${ }^{\mathrm{TM}}$ It was not possible to measure hardness (breakpoint) SD in metformin tablets beyond four weeks, as the tablets had become softened. After four weeks, major changes in breakpoint occurred in the original container. Changes were significant in original container after six months $(\mathrm{SD}=+101.9696)$. Dissolution time also changed from baseline, with significant changes in both Webster-Pak ${ }^{\mathrm{TM}}$ and MedicoPak ${ }^{\mathrm{TM}}$.

\section{Amiodarone}

Most changes in the API level and $\mathrm{pH}$ changes were in Webster-Pak ${ }^{\mathrm{TM}}$. The changes in break point in the original pack were more significant than in the repackaged samples were the dissolution time changes were significant but similar in both repacks and original pack.

\section{Amlodipine}

Most changes in the API level were seen in the Webster$\mathrm{Pak}^{\mathrm{TM}}$. Changes in $\mathrm{pH}$ occurred only in MedicoPak ${ }^{\mathrm{TM}}$ and bottles. The changes in breakpoint for amlodipine were seen in all containers where the changes in the dissolution time were significant and slightly higher in Webster-Pak ${ }^{\mathrm{TM}}$ than all other containers.

\section{Aspirin}

Most changes in the API level and $\mathrm{pH}$ were seen in the repackaged bottles and not in the original containers. The changes in the breakpoint in original pack were less significant than in the repackaged samples. Dissolution time also changed from baseline; the changes in the original pack were less significant than in the repackaged samples.

\section{Atorvastatin}

Most changes in the API level were seen in the WebsterPak where changes in the $\mathrm{pH}$ occurred in all containers. It was not possible to measure the breakpoint beyond four weeks as the tablets had softened. After the first four week, most changes in breakpoint occurred in original container after6 months it was also significantly high in the original container. The changes in dissolution time in the original pack were less significant than that in the repackaged samples.

\section{Gliclazide}

The changes in gliclazide level and $\mathrm{pH}$ were most seen in the repacks when compared to the original containers. The changes in breakpoint were less significant in original bottle than that in the repackaged samples in the first four weeks. It was not possible to be measured in beyond four weeks, as the tablets softened, but after six months it was significantly high in original control ( $\mathrm{SD}=7.460362)$. Dissolution time also changed from that measured at baseline; the changes in the original pack were less significant than in the repackaged samples.

\section{Ibuprofen}

Most changes in the API level were seen in the Webster$\mathrm{Pak}^{\mathrm{TM}}$. The $\mathrm{pH}$ changes occurred in all repackaged samples when compared to original pack. The changes in breakpoint the original pack and in the repackaged samples were similar and significant. Dissolution time changes in the original pack were less significant than in the repackaged samples.

\section{Irbesartan}

Most changes in irbesartan stability during the six-month study period were seen in the MedicoPak ${ }^{\mathrm{TM}}$ where the changes in $\mathrm{pH}$ occurred mostly in MedicoPak ${ }^{\mathrm{TM}}$ and Webster-Pak ${ }^{\mathrm{TM}}$. The changes in breakpoint for irbesartan original pack were less significant than that in the repackaged samples. Dissolution time changes in the original pack were less significant than in the repackaged samples.

\section{Paracetamol}

The changes in paracetamol stability and $\mathrm{pH}$ after sixmonth study period were seen in all containers. While the tablets did not soften, they had high moisture content after Week 4 resulting in similar and significant changes in the breakpoint in all packs. Dissolution time changes in the original pack were less significant than in the repackaged samples.

\section{Prednisolone}

Most of the changes in prednisolone stability during the six-month study period were seen in the original pack and repacked bottles. Similar significant changes for $\mathrm{pH}$ and breakpoint were significant and occurred in all containers. Dissolution time changes in the original pack were less significant than in the repackaged samples.

\section{Sodium valproate}

The most changes in the API level were seen in the Webster-Pak ${ }^{\mathrm{TM}}$ with no change seen in original packs where the change in $\mathrm{pH}$ occurred in all containers. The change in breakpoint for sodium valproate were significant in all containers. It was not possible to measure beyond two weeks as the tablets softened. 
Dissolution time changes in the original pack were less significant than in the repackaged samples. Dissolution rate was not possible to be measure beyond two weeks as the tablets softened and disintegrated.

\section{Microbiology investigation}

As soon as the products were received from the supplier on Day 1, a sterile spreader was used to swab the inside and outside of the original container and the tablet surface, and then used to distribute the inoculum over the surface of already prepared culture plates. Two types of plates were used - nutrient agar plates for bacteria detection and Sabouraud Agar plates for fungus detection. An incubation period of 24 hours for nutrient agar plates and 72 hours for sabouraud agar plates was selected.

There was a bacterial growth detected on the paracetamol container, and on the metformin and sodium valproate original boxes. There was also some fungal growth detected on the amiodarone, gliclazide, metformin, paracetamol and prednisolone original containers.

After seven days in the temperature and humidity controlled chamber, the tablets and their containers were swabbed and cultured. There was bacterial growth detected on and in the paracetamol container and on the metformin and sodium valproate original packs. There was also some fungal growth detected on the amiodarone, gliclazide, metformin, paracetamol and prednisolone original containers. There was bacterial growth detected on and/or in the repackaged bottles for amiodarone, atorvastatin, metformin, paracetamol and sodium valproate. There was also fungal growth detected on the amiodarone, gliclazide, metformin, paracetamol and prednisolone repackaged bottles and on the ibuprofen tablet surface.

There was bacterial growth detected on and in the Webster-Pak ${ }^{\mathrm{TM}}$ for paracetamol, amiodarone, atorvastatin, irbesartan, metformin and sodium valproate, and there was also growth on the gliclazide tablet surface. There was fungal growth detected on the amiodarone, gliclazide, metformin, paracetamol and prednisolone Webster-Pak ${ }^{\mathrm{TM}}$ and on the ibuprofen and sodium valproate tablet surfaces. There was bacterial growth detected on and in the MedicoPak ${ }^{\mathrm{TM}}$ for amiodarone, atorvastatin, irbesartan, paracetamol, metformin and sodium valproate, and growth on the gliclazide tablet surface. There was also fungal growth detected on the amiodarone, gliclazide, metformin and prednisolone MedicoPak ${ }^{\mathrm{TM}}$ and on the ibuprofen and sodium valproate tablet surfaces.

After 14 days in the temperature and humidity controlled chamber the tablets and their containers were swabbed and cultured. There was bacterial growth detected on and in the paracetamol container and on the sodium valproate original packs. There was also some fungal growth detected on the amiodarone, gliclazide, metformin and paracetamol original containers. There was bacterial growth detected on and in the aspirin, irbesartan, paracetamol and sodium valproate repackaged bottles and on the amiodarone tablet surface. There was also fungal growth detected on the aspirin, irbesartan, paracetamol and prednisolone repackaged bottles and on the amiodarone, gliclazide and sodium valproate tablet surfaces.

There was bacterial growth detected on and in the Webster-Pak ${ }^{\mathrm{TM}}$ for aspirin, paracetamol, amiodarone, gliclazide, irbesartan and sodium valproate, there was no growth on the tablet surfaces. There was also fungal growth detected on the amiodarone, aspirin, gliclazide, irbesartan, metformin and prednisolone Webster-Pak ${ }^{\mathrm{TM}}$ and on the amlodipine and paracetamol tablet surfaces. There was bacterial growth detected on and in the MedicoPak ${ }^{\mathrm{TM}}$ for amiodarone, aspirin, gliclazide, atorvastatin, irbesartan, paracetamol and sodium valproate, there was no growth on tablet surfaces. There was also fungal growth detected on the amlodipine, ibuprofen, metformin and prednisolone MedicoPak ${ }^{\mathrm{TM}}$ and on the sodium valproate tablet surfaces.

After 28 days in the temperature and humidity controlled chamber the tablets and their containers were swabbed and cultured. There was bacterial growth detected on and in the amiodarone, paracetamol, aspirin and sodium valproate original containers. There was also fungal growth detected on the amiodarone, amlodipine, atorvastatin, metformin and prednisolone original containers (control) and on the irbesartan tablet surface. There was bacterial growth detected on and in the amiodarone, aspirin, gliclazide, irbesartan, paracetamol and sodium valproate repackaged bottles. There was also fungal growth detected on the gliclazide and paracetamol repackaged bottles and on the amiodarone, aspirin, irbesartan and sodium valproate tablet surfaces. There was bacterial growth detected on and in the Webster-Pak ${ }^{\mathrm{TM}}$ for aspirin, amiodarone, gliclazide, ibuprofen, metformin, prednisolone and sodium valproate; there was no growth on the tablet surfaces. There was also fungal growth detected on the amiodarone, aspirin, gliclazide, ibuprofen, metformin and sodium valproate tablet surfaces and on the prednisolone Webster-Pak ${ }^{\mathrm{TM}}$. There was bacterial growth detected on and in the MedicoPak ${ }^{\mathrm{TM}}$ for amlodipine, aspirin, gliclazide, irbesartan, metformin, prednisolone and sodium valproate, there was no growth on tablet surfaces. There was also fungal growth detected on the amlodipine, aspirin, gliclazide, ibuprofen, metformin, prednisolone and sodium valproate packed in MedicoPak ${ }^{\mathrm{TM}}$ on the surface of the tablets.

After three months in the temperature and humidity controlled chamber the tablets and their containers were swabbed and cultured. There was bacterial growth detected on and in the atorvastatin, paracetamol, irbesartan and sodium valproate original containers. There was also fungal growth detected on the amiodarone, gliclazide, ibuprofen and prednisolone original containers. There was bacterial growth detected on and in the amiodarone, amlodipine, atorvastatin, gliclazide, irbesartan, metformin, prednisolone and sodium valproate repackaged bottles. There was also fungal growth detected on the amlodipine, atorvastatin, gliclazide and ibuprofen, metformin, prednisolone and sodium valproate tablet surfaces in the repackaged bottles. There was bacterial growth detected on and in the Webster-Pak ${ }^{\mathrm{TM}}$ for amlodipine, aspirin, gliclazide, irbesartan, metformin, 
prednisolone and sodium valproate, there was no growth on the tablet surfaces. There was also fungal growth detected on the aspirin, gliclazide, ibuprofen, metformin, prednisolone and sodium valproate packed in Webster-Pak ${ }^{\mathrm{TM}}$ on the surface of the tablets. There was bacterial growth detected on and in the MedicoPak ${ }^{\mathrm{TM}}$ for amlodipine, gliclazide, atorvastatin, metformin, prednisolone and sodium valproate; there was no growth on tablet surfaces. There was also fungal growth detected on the amiodarone, amlodipine, atorvastatin, gliclazide, ibuprofen, metformin, prednisolone and sodium valproate packed in MedicoPak ${ }^{\mathrm{TM}}$ on the surface of the tablets. After six months in the temperature and humidity controlled chamber the tablets and their containers were swabbed and cultured. There was bacterial growth detected on and/or in the amiodarone and amlodipine original containers. There was also fungal growth detected on the aspirin, gliclazide, paracetamol and prednisolone original containers. There was bacterial growth detected on and in the amlodipine, aspirin, ibuprofen, metformin, prednisolone and sodium valproate repackaged bottles, there was bacterial growth on irbesartan tablet surface. There was also fungal growth detected on the gliclazide and metformin on the bottle surface and there was fungal growth on the amlodipine, atorvastatin, ibuprofen, metformin, prednisolone and sodium valproate tablet surfaces in the repackaged bottles. There was bacterial growth detected on and in the Webster-Pak ${ }^{\mathrm{TM}}$ for aspirin, amlodipine, ibuprofen, metformin, prednisolone and sodium valproate, and there was bacterial growth on the irbesartan tablet surface. There was also fungal growth detected on the amlodipine, atorvastatin, ibuprofen, metformin, prednisolone and sodium valproate packed in Webster-Pak ${ }^{\mathrm{TM}}$ on the surface of the tablets and on the amlodipine and on the Webster-Pak ${ }^{\mathrm{TM}}$ for gliclazide and paracetamol. There was bacterial growth detected on and in the MedicoPak ${ }^{\mathrm{TM}}$ for metformin, paracetamol and sodium valproate; there was no growth on tablet surfaces. There was also fungal growth detected on the amiodarone, metformin, paracetamol and prednisolone MedicoPak ${ }^{\mathrm{TM}}$ outside surface.

\section{DISCUSSION}

The findings from this study can be used as a baseline for further investigations. This study was carried out on frequently prescribed medicines in immediate (traditional) release tablet formulations that are used for cardiovascular diseases, diabetes, arthritis and respiratory conditions such as COPD (chronic obstructive pulmonary disease) or asthma. The 11 medicines chosen were aspirin, paracetamol, metformin, atorvastatin, irbesartan, amlodipine, amiodarone, gliclazide, ibuprofen and prednisolone.

\section{Active pharmaceutical ingredient stability and physical changes}

The WHO guidelines of 1998recommend that the storage labeling statement should be: Store at $25{ }^{\circ} \mathrm{C}$; excursions permitted to $15-30{ }^{\circ} \mathrm{C}(42)$. If storage remains within the manufacturer's recommended range, the proposed shelf life can be maintained.
This study investigated the stability of pharmaceuticals stored in a tropical environment where heat and humidity exceeds that described by manufacturers, and in many occasions room temperature exceeds $30^{\circ} \mathrm{C}$, especially in the housing of lower socioeconomic patients where air-conditioning is not available. Additionally, when medication is exposed to these conditions (heat and humidity) and in many cases, directly exposed to the sun, soil or rain (if the patient is homeless or living outdoors) can also compromise the physical characteristics of the tablets.

The study tested the stability of the medications through quantifying the amount of API after exposure to heat and humidity from seven days to 24 weeks. The study also measured any change in appearance, dissolution and disintegration of the medications in both the manufacturer's original container and in the repackaged DAAs or bottles. Although there are few studies on the stability and therefore the efficacy and safety of medicines during packing and storage, and consequently little data, this study provides new evidence of the stability of enteric coated sodium valproate when repackaged in DAAs. It is important however, that DAAs are stored in a cool, dry place protected from light, for example inside lockable chambers. Monitoring the integrity of DAAs throughout the usage period is recommended, since DAAs may be subjected to a reasonable amount of handling, inadequate sealing due to change in the glue effectiveness in the hot and humid environment and accidental puncture of the blister seals, which may further increase the possibility of the exposure to intensive levels of heat and humidity that exceeds the manufacturer's recommendations. Baseline testing indicated that the starting product met all parameters as indicated in the drug product information and the Pharmaceopeial limits. The current literature on the effect of temperature on hardness of organic materials indicates that an increase in temperature affects the sucrose used in coating tablets. The effect on coating was found to reduce the indentation hardness of the tablets (Olusanmi, 2010). The increase in temperature and humidity may also increase the permeability of the PVC bottles or sheets used to make the blister packs which can also affect the tablet hardness due to moisture absorption (Olusanmi, 2010). The increase in hardness due to loss of moisture is further accelerated at temperatures greater than room temperature (Olusanmi, 2010).

Water absorption increases when the temperature exceeds $23{ }^{\circ} \mathrm{C}$ for 24 hours, thermal conductivity increases when the temperature exceeds $50^{\circ} \mathrm{C}$ and thermal diffusivity also increases when the temperature exceeds $50^{\circ} \mathrm{C}$ (Olusanmi, 2010). In this study, a temperature of $30{ }^{\circ} \mathrm{C}$ and humidity of $80 \% \mathrm{RH}$ were used, which affected most measured parameters; however, some were affected more than others. Similar results were reported by another study where the authors found that temperature and humidity reduced both the hardness and fracture toughness of aspirin (Olusanmi, 2010). In this current study, while changes occurred in the original pack, they were less significant than that in the repackaged samples, where bottles had the most significant change. Hosny's (1999) study compared the stability of indomethacin tablets under different combinations of temperature and $\mathrm{RH}\left(30{ }^{\circ} \mathrm{C} / 92.9 \% \mathrm{RH}, 40^{\circ} \mathrm{C} / 79.5 \% \mathrm{RH}\right.$ and $50^{\circ} \mathrm{C} / 65 \% \mathrm{RH}$ for 
16 weeks) and tested at two, four, eight, 12 and 16 weeks, where in this study fixed temperature and $\mathrm{RH}\left(30^{\circ} \mathrm{C} / 80 \% \mathrm{RH}\right)$ were used and stability and physical characteristics of tablets were tested at intervals of one, two, and four weeks, then after three and six months in four different packaging materials. Hosny (1999) measured tablet weight, which was not measured in this current study (Olusanmi, 2010).

Hosny (1999) found that the tablet's mean weight significantly increased at $30^{\circ} \mathrm{C} / 98 \% \mathrm{RH}$, when compared to $40^{\circ} \mathrm{C} / 79.3 \% \mathrm{RH}$, and $50^{\circ} \mathrm{C} / 65 \% \mathrm{RH}$, and proportional hardness was reduced - becoming zero at $30^{\circ} \mathrm{C} / 98 \% \mathrm{RH}$ and $92.9 \% \mathrm{RH}$, which corresponds to the results from this current study at threemonth and six-month testing. All 11 tested medications underwent changes (reduction) in hardness in their original containers, except aspirin and paracetamol that remained unchanged. In the repackaged bottles, Webster-Pak ${ }^{\mathrm{TM}}$ and MedicoPak ${ }^{\mathrm{TM}}$, aspirin and paracetamol remained the same, while amiodarone, amlodipine, ibuprofen, irbesartan and prednisolone reduced, and atorvastatin, gliclazide, metformin and sodium valproate became zero.

The API amount measured at baseline remained unchanged for gliclazide and metformin, with a changed SD of between 0.070 (amlodipine) and 0.636 in atorvastatin (Table 7) in all containers. The $\mathrm{pH}$ also changed from baseline to six months, with the most significant change seen in metformin; however, there were no other studies found to compare this finding to (Table 8). Hosny (1999) found that tablets stored at $30^{\circ} \mathrm{C}$ with $98 \%$ and $92 \%$ RH showed an increase in disintegration time (Hosny, 1999). The moisture uptake resulted in an increase in tablet weight, a decrease in tablet hardness and faster tablet dissolution rate (Hosny, 1999). The results for the repackaged containers were similar to the results of this current study, where amiodarone had the most significant change. No changes to tablet appearance were seen during the first 28 days. In week four; sodium valproate became soft and disintegrated in almost all repackaged containers. Table 9 shows the disintegrated tablets in a Webster-Pak ${ }^{\mathrm{TM}}$. By the third month, samples of atorvastatin, gliclazide and metformin also were disintegrated. The results are comparable to that of Hosny (1999). These research findings highlight the need for storing DAAs in controlled environments for those patients living in hot and humid climates. Healthcare professionals can play an important role in advising patients, caregivers and other members of the healthcare team on the stability of medications and the importance of packaging, storing and using them correctly.

Table 7: Change in active pharmaceutical ingredient absorbance from baseline to six months.

\begin{tabular}{llll}
\hline Drug & Absorbance at baseline & Absorbance at six months & SD \\
\hline Amiodarone & 1.9 & 1.7 & 0.141421 \\
Amlodipine & 1.6 & 1.5 & 0.070711 \\
Aspirin & 1.9 & 1.4 & 0.353553 \\
Atorvastatin & 4.6 & 3.7 & 0.636396 \\
Gliclazide & 3.5 & 3.5 & 0 \\
Ibuprofen & 1.8 & 1.6 & 0.141421 \\
Irbesartan & 5.5 & 5.3 & 0.141421 \\
Metformin & 3.6 & 3.6 & 0 \\
Paracetamol & 4.4 & 3.6 & 0.565685 \\
Prednisolone & 3.38 & 3.7 & 0.226274 \\
Sodium Valproate & 4.2 & 4.0 & 0.141421 \\
\hline
\end{tabular}

Table 8: Change in $\mathrm{pH}$ from baseline to six months.

\begin{tabular}{lllllll}
\hline Drug & Baseline & Original & Bottle & Webster-Pak $^{\text {TM }}$ & Medico-Pak $^{\text {TM }}$ & SD \\
\hline Amiodarone & 40 & 4.5 & 5.0 & 5.0 & 4.5 & 0.41833 \\
Amlodipine & 5.5 & 5.0 & 5.5 & 5.5 & 5.0 & 0.2738613 \\
Aspirin & 3.0 & 4.0 & 4.0 & 4.0 & 4.0 & 0.4472136 \\
Atorvastatin & 7.0 & 6.0 & 6.5 & 6.5 & 6.0 & 0.41833 \\
Gliclazide & 5.5 & 5.5 & 6.0 & 6.0 & 5.5 & 0.2738613 \\
Ibuprofen & 4.5 & 5.0 & 5.0 & 5.0 & 6.0 & 0.2236068 \\
Irbesartan & 5.5 & 5.5 & 6.0 & 6.0 & 5.5 & 0.2738613 \\
Metformin & 6.5 & 6.5 & 5.5 & 5.5 & 6.0 & 0.547226 \\
Paracetamol & 6.0 & 6.5 & 6.5 & 6.5 & 6.0 & 0.2738613 \\
Prednisolone & 5.5 & 6.5 & 6.5 & 6.5 & 6.0 & 0.2738613 \\
Sodium Valproate & 6.0 & 6.5 & & & & \\
\hline
\end{tabular}

Table 9: Dissolution time from baseline to six months.

\begin{tabular}{|c|c|c|c|c|c|c|}
\hline Drug & Baseline & Original & Bottle & Webster-Pak $^{\mathrm{TM}}$ (sec) & Medico-PakT ${ }^{\mathrm{TM}}$ (sec) & SD \\
\hline Amiodarone & $3: 02$ & $7: 54$ & $8: 34$ & $8: 44$ & $8: 44$ & 0.102558889 \\
\hline Amlodipine & $0: 36$ & $3: 35$ & $3: 44$ & $3: 54$ & $3: 54$ & 0.059494884 \\
\hline Aspirin & $0: 27$ & $4: 05$ & $5: 23$ & $5: 43$ & $5: 43$ & 0.093291575 \\
\hline Atorvastatin & $6 .: 32$ & 10:09 & $10: 25$ & $10: 35$ & $11: 05$ & 0.016369849 \\
\hline Gliclazide & $2: 38$ & $4: 34$ & $7: 04$ & $6: 54$ & $7: 45$ & 0.088791179 \\
\hline Ibuprofen & $5: 08$ & $7: 43$ & $9: 56$ & 11:08 & $9: 05$ & 0.095985437 \\
\hline Irbesartan & $4: 11$ & $6: 19$ & $6: 35$ & $6: 40$ & $6: 08$ & 0.042697322 \\
\hline Metformin & $11: 35$ & $15: 03$ & $14: 35$ & $14: 45$ & $14: 45$ & 0.060039532 \\
\hline Paracetamol & $2: 21$ & 3:09 & $5: 20$ & $5: 28$ & $5: 45$ & 0.0645359 \\
\hline Prednisolone & $1: 38$ & $3: 48$ & $5: 32$ & $5: 35$ & $5: 43$ & 0.073416606 \\
\hline Sodium Valproate & $1: 25: 53$ & $1: 11: 23$ & 0 & 0 & 0 & 0.030120335 \\
\hline
\end{tabular}


Table 10: Changes after 6 months in the controlled temperature and humidity cabinet (unless otherwise specified).

\begin{tabular}{|c|c|c|c|c|c|}
\hline Medications & Comments & $\begin{array}{c}\text { Absorbance } \\
\text { SD }\end{array}$ & $\begin{array}{l}\text { pH } \\
\text { SD } \\
\end{array}$ & $\begin{array}{c}\text { Breakpoint } \\
\text { SD }\end{array}$ & $\begin{array}{c}\text { Dissolution time } \\
\text { SD }\end{array}$ \\
\hline \multirow{4}{*}{ Metformin } & Original pack & 0.044721 & 0.273861 & $73.92789^{*}$ & 0 \\
\hline & Bottle & 0.054772 & 0.273860 & $69.46222^{*}$ & 0 \\
\hline & Webster-Pak ${ }^{\mathrm{TM}}$ & 0 & 0.447213 & $66.39528^{*}$ & 0.113376 \\
\hline & MedicoPak ${ }^{\mathrm{TM}}$ & 0.044721 & 0.447214 & $60.57953 *$ & 0.111385 \\
\hline \multirow{4}{*}{ Amiodarone } & Original pack & 0.04 & 0 & 19.29045 & 0.110189 \\
\hline & Bottle & 0.101980 & 0.244949 & 10.16065 & 0.131130 \\
\hline & Webster-Pak ${ }^{\mathrm{TM}}$ & 0.12 & 0.400000 & 9.321052 & 0.134800 \\
\hline & MedicoPak $^{\mathrm{TM}}$ & 0.063246 & 0 & 10.11002 & 0.133336 \\
\hline \multirow{4}{*}{ Amlodipine } & Original pack & 0 & 0 & 32.01273 & 0.055649 \\
\hline & Bottle & 0.114018 & 0.223607 & 24.36458 & 0.068461 \\
\hline & Webster-Pak $^{\mathrm{TM}}$ & 0.151658 & 0 & 24.81929 & 0.073573 \\
\hline & MedicoPak $^{\mathrm{TM}}$ & 0.114018 & 0.223607 & 24.59263 & 0.072200 \\
\hline \multirow{4}{*}{ Aspirin } & Original pack & 0 & 0 & 24.67766 & 0.073186 \\
\hline & Bottle & 0.114018 & 0.447214 & 27.82490 & 0.108683 \\
\hline & Webster-Pak ${ }^{\mathrm{TM}}$ & 0.089443 & 0.447214 & 25.69431 & 0.111006 \\
\hline & MedicoPak $^{\mathrm{TM}}$ & 0.114018 & 0.447214 & 26.19248 & 0.109988 \\
\hline \multirow{4}{*}{ Atorvastatin } & Original pack & 0.044721 & 0.223607 & $15.76166^{*}$ & 0.070674 \\
\hline & Bottle & 0.141421 & 0.447214 & $8.834214^{*}$ & 0.095772 \\
\hline & Webster-Pak ${ }^{\mathrm{TM}}$ & 0.194936 & 0.273861 & $5.221430^{*}$ & 0.114725 \\
\hline & MedicoPak $^{\mathrm{TM}}$ & 0.089443 & 0.418330 & $5.164301^{*}$ & 0.125603 \\
\hline \multirow{4}{*}{ Gliclazide } & Original pack & 0 & 0 & $4.990324 *$ & 0.041701 \\
\hline & Bottle & 0.089443 & 0.223607 & $3.143247 *$ & 0.092909 \\
\hline & Webster-Pak $^{\mathrm{TM}}$ & 0.109545 & 0.353553 & $3.557152 *$ & 0.095125 \\
\hline & MedicoPak $^{\mathrm{TM}}$ & 0.054772 & 0.223607 & $3.857460 *$ & 0.107431 \\
\hline \multirow{4}{*}{ Ibuprofen } & Original pack & 0.044721 & 0.273861 & 32.49441 & 0.052040 \\
\hline & Bottle & 0.122474 & 0.273861 & 30.61723 & 0.102585 \\
\hline & Webster-Pak $^{\mathrm{TM}}$ & 0.181659 & 0.273861 & 22.18889 & 0.119976 \\
\hline & MedicoPak ${ }^{\mathrm{TM}}$ & 0.083666 & 0.273861 & 24.93538 & 0.106582 \\
\hline \multirow{4}{*}{ Irbesartan } & Original pack & 0.089443 & 0 & 0.581378 & 0.044483 \\
\hline & Bottle & 0.134164 & 0 & 3.401176 & 0.064780 \\
\hline & Webster-Pak ${ }^{\mathrm{TM}}$ & 0.698570 & 0.223607 & 3.105238 & 0.073554 \\
\hline & MedicoPak $^{\mathrm{TM}}$ & 0.831865 & 0.353553 & 3.426368 & 0.067940 \\
\hline \multirow{4}{*}{ Paracetamol } & Original pack & 0.089443 & 0.223607 & 34.15804 & 0.016667 \\
\hline & Bottle & 0.194936 & 0.353553 & 41.47804 & 0.062867 \\
\hline & Webster-Pak ${ }^{\mathrm{TM}}$ & 0.044721 & 0.353553 & 61.35852 & 0.075129 \\
\hline & MedicoPak $^{\mathrm{TM}}$ & 0.178885 & 0.223607 & 54.23088 & 0.080842 \\
\hline \multirow{4}{*}{ Prednisolone } & Original pack & 0.178885 & 0.223607 & 8.707353 & 0.045166 \\
\hline & Bottle & 0.089443 & 0.223607 & 4.977148 & 0.083520 \\
\hline & Webster-Pak ${ }^{\mathrm{TM}}$ & 0.260768 & 0.223607 & 6.069761 & 0.091492 \\
\hline & MedicoPak $^{\mathrm{TM}}$ & 0.089443 & 0.223607 & 5.996916 & 0.094204 \\
\hline \multirow{4}{*}{ Sodium valproate } & Original pack & 0 & 0.223607 & $1.555635^{* *}$ & $0.009821 * *$ \\
\hline & Bottle & 0.089443 & 0.273861 & $4.454773 * *$ & $0.000581 * *$ \\
\hline & Webster-Pak ${ }^{\mathrm{TM}}$ & 0.271993 & 0.273861 & $2.828427 * *$ & $0.000131 * *$ \\
\hline & MedicoPakTM $^{\mathrm{TM}}$ & 0.054772 & 0.223607 & $6.010408 * *$ & $0.000246 * *$ \\
\hline
\end{tabular}

*Duration of four weeks

**Duration of two weeks

\section{Microbiology investigation}

Akerele et al. (2002) concluded that on microbiological examination of tablets dispensed from large containers in hospitals and community pharmacies there was growth of both aerobic bacteria and fungi detected (Gunar, 2011). The aerobic organisms were mainly Bacillus species and Streptococci (Akerele and Ukoh, 2011).

The frequent occurrence of enterobacteria among ascorbic acid and folic tablets from hospital and community pharmacies were compared (Akerele and Ukoh, 2011). Among the fungi encountered with the tablets were Microsporum spp, Penicillium spp, Trichophyton, Aspergillus, Cephalosporium and Epidermophyton (Akerele and Ukoh, 2011). In this current study, there was contamination by microorganisms in both the original and repackaged containers. However, after one week, growth was found on both the outer and inner surface of all containers, including the original pack. Growth on the surface of the tablets was not consistent, and might have been related to the packing of that container rather than the batch. In Week 2 there was bacterial growth on the amiodarone tablet surface, but it was not found again. Similarly, bacterial growth was found for gliclazide in Week 1, and sodium valproate and irbesartan in month 6 . Occurrences of bacterial growth were apparent in all types of packaging used for re-packaging. Fungal growth was different; it was seen on and in all repackaged containers, and on the surface of all tablets from Week 4 to Month 6, which further indicates the greater effect of humidity and temperature together, rather than humidity alone. 


\section{Limitations}

- Due to the short time of the master by research candidature, there were some limitations imposed on the methodology:

- A small sample of medications was used to reduce the cost $(n=11)$.

- There was one set of temperature and $\mathrm{RH}$ used $(30 \circ \mathrm{C} / 80 \% \mathrm{RH})$ instead of different combinations of temperature and $\mathrm{RH}$ at the set time of testing to replicate previous studies (Hosny, 1999).

- The study did not include capsules or other specialized release tablets such as sublingual or wafers.

- This preliminary study has demonstrated that products stored in tropical conditions changed in their characteristics and also gained microbial contamination during the processing. Further research is required to fully characterize the problem.

\section{CONCLUSION}

Re-packaging and re-labeling of medications are currently common practice for patients on discharge from hospital, or for those taking multiple medications that require management to avoid patient confusion, often by re-packaging into a DAA. Additionally, re-packaging and re-labeling is common practice for dispensing all prescriptions in countries where bulk medication containers are used. This practice personalize medication for individual patients.

This study contributes meaningful data to current practice. The process for determining stability (chemical and physical) of pharmaceuticals outside the manufacture container is complex because of the various factors that influence the stability of pharmaceutical products. However, it is an important area for further research because medication should treat a medical condition, not create a new problem.

\section{Financial support and sponsorship: Nil.}

Conflict of Interests: There are no conflicts of interest.

\section{REFERENCES}

Akerele JO, Ukoh GC. Aspects of microbial contamination of tablets dispensed in hospitals and community pharmacies in Benin City, Nigeria. Trop J Pharmaceut Res, 2011; 1(1):23-28.

Bureau of Meteorology. Average annual \& monthly maximum, minimum, \& mean temperature. Available at: http://www.bom.gov.au/jsp/ncc/climate_averages/temperature/index.jsp

Bentley J, Heard K, Collins G, Chung C. Mixing medicines: how to ensure patient safety. Pharm J, 2015;DOI: 10.1211/PJ.2015.20068289.

British Pharmacopoeia. 2008. Efficacy of antimicrobial preservation. British Pharmacopoeia, volume IV, appendix XVI C. Ph. Eur. General Text 5.1.3.[ONLINE] Available at: http://www.uspbpep.com/bp2008/data/842.asp. [Accessed 09 May 2017].

Bott RF, Oliveira WP. Storage conditions for stability testing of pharmaceuticals in hot and humid regions. Drug DevelInd Pharm, 2007; 33(4):393-401.

Charde MS, Shinde MM, Welankiwar AS, Jitendra K. Development of analytical and stability testing method for vitamin-A palmitate formulation. Int J PharmaceutChem, 2014; 4(1):39-51.

Department of Health and Human Services US Food and Drug Administration.2004. Pharmaceutical CGMPs for the 21st century — a risk-based approach: final report. [ONLINE] Available at https://www.fda.gov/downloads/drugs/developmentapprovalprocess/manu facturing/questionsandanswersoncurrentgoodmanufacturingpracticescgmp fordrugs/ucm176374.pdf. [Accessed 09 May 2017].

Edirisinghe S, Raimi-Abraham BT, Gilmartin JF-M, Orlu-Gul M. Multi-compartment compliance aids (MCAs): Application to the geriatric community. EurGeriatr Med, 2014; 6(1):65-68.

Feng X, Ye X, Park JB, Lu W, Morott J, Beissner B, Lian ZJ, Pinto E, Bi V, Porter S,Durig T,Majumdar S,Repka MA.Evaluation of the recrystallization kinetics of hot-melt extruded polymeric solid dispersions using an improved Avrami equation, Drug Dev IndPharm, 2014; 41(9):1479-1487.

Feng X, Vo A, Patil H, Tiwari RV, Alshetaili AS, Pimparade MB, Repka MA. The effects of polymer carrier, hot melt extrusion process and downstream processing parameters on the moisture sorption properties of amorphous solid dispersions. J Pharm Pharmacol, 2016; 68(5):692-704.

Grimm W. Extension of the International Council for Harmonisation Tripartite Guideline for Stability Testing of New Drug Substances and Products to countries of Climatic zones III and IV. Drug Dev Ind Pharm, 1998;24(4):313-325.

Gunar OV. Aspects of investigating microflora contamination of drugs (a review). PharmaceutChem J, 2011; 45(2):93-102.

Hosny EA. Study of accelerated storage conditions affecting physical characteristics, in-vitro dissolution and stability of bioadhesive containing tablets. B ChimFarmaceut, 1999; 138(6):243-248.

International Council for Harmonisation Expert Working Group. 2009. Guidance for industry Q10 pharmaceutical quality system. U.S. Department of Health and Human Services Food and Drug Administration. [ONLINE] Available at https://www.fda.gov/downloads/Drugs/.../Guidances/ucm073517.pdf. [Accessed 09 May 2017].

Liu X, Lu M, Guo Z, Huang L, Feng X, Wu C. Improving the chemical stability of amorphous solid dispersion with co-crystal technique by hot melt extrusion, Pharmaceut Res, 2011; 29(3): 806-817.

NiDirect Government Services. 2017. Disabled people's rights in everyday life. [ONLINE] Avilable at https://www.nidirect.gov.uk/articles/disabled-peoples-rights-everyday-life. [Accessed 09 May 2017].

Okunlola A, Adewoyin BA, Odeku OA. Evaluation of pharmaceutical and microbial qualities of some herbal medicinal products in south western Nigeria. Trop J Pharmaceut Res, 2007; (6)1:661-70.

Olusanmi CW, Ghadiri M, Ding Y, Roberts KJ. Effect of temperature and humidity on the breakage behaviour of aspirin and sucrose particles. Powder Technol, 2010; 201(3):248-252.

Pilchik R. Pharmaceutical blister packaging, part I: Rationale and materials. PharmaceutTechnol, 2000a; 24(11):68-78.

Pilchik R. Pharmaceutical blister packaging, part II: Machinery and assembly. PharmaceutTechnol, 2000b; 24(12):56-60.

World Health Organization. 2003. The international pharmacopoeia, vol. 5. Tests and general requirements for dosage forms; Quality specifications for pharmaceutical substances and tablets. 3rd ed. [ONLINE] Available at: https://pharmafed.files.wordpress.com/2013/04/internationalpharmacopia.pdf. [Accessed 09 May 2017].

Zadbuke N, Shahi S, Gulecha B, Padalkar A, Thube M. Recent trends and future of pharmaceutical packaging technology. J Pharm Bioallied Sci, 2013; 5(2):98-110.

\section{How to cite this article:}

Raman B, Morrissey H, Ball P. Pharmaceuticals in the tropics: A quantitative study measuring changes in quantity of the active ingredient and microbiological growth. J App Pharm Sci, 2017; 7 (09): 160-170. 